\title{
Levers of change: a review of contemporary interventions to enhance diversity in medical schools in the USA
}

This article was published in the following Dove Press journal:

Advances in Medical Education and Practice

\author{
Alexis Danielle Vick' \\ Aaron Baugh ${ }^{2}$ \\ Julie Lambert ${ }^{\prime}$ \\ Allison A Vanderbilt ${ }^{3}$ \\ Evan Ingram' \\ Richard Garcia ${ }^{4}$ \\ Reginald F Baugh ${ }^{5}$ \\ 'College of Medicine and Life \\ Sciences, ${ }^{2}$ Department of Internal \\ Medicine, ${ }^{3}$ Department of Family \\ Medicine, College of Medicine and \\ Life Science, University of Toledo, \\ Toledo, $\mathrm{OH},{ }^{4}$ Consultant, The Ethnic \\ Health Institute, Oakland, CA, \\ ${ }^{5}$ Department of Surgery, College of \\ Medicine and Life Sciences, University \\ of Toledo, Toledo, $\mathrm{OH}$, USA
}

\begin{abstract}
A growing body of research illustrates the importance of aligning efforts across the operational continuum to achieve diversity goals. This alignment begins with the institutional mission and the message it conveys about the priorities of the institution to potential applicants, community, staff, and faculty. The traditional themes of education, research, and service dominate most medical school mission statements. The emerging themes of physician maldistribution, overall primary-care physician shortage, diversity, and cost control are cited less frequently. The importance and salience of having administrative leaders with an explicit commitment to workforce and student diversity is a prominent and pivotal factor in the medical literature on the subject. Organizational leadership shapes the general work climate and expectations concerning diversity, recruitment, and retention. Following the Bakke decision, individual medical schools, supported by the Association of American Medical Colleges, worked to expand the frame of reference for evaluating applicants for medical school. These efforts have come together under the rubric of "holistic review", permitted by the US Supreme Court in 2003. A large diverseapplicant pool is needed to ensure the appropriate candidates can be chosen for the incoming medical school class. Understanding the optimal rationale and components for a successful recruitment program is important. Benchmarking with other schools regionally and nationally will identify what should be the relative size of a pool. Diversity is of compelling interest to us all, and should pervade all aspects of higher education, including admissions, the curriculum, student services and activities, and our faculties. The aim of medical education is to cultivate a workforce with the perspectives, aptitudes, and skills needed to fuel community-responsive health-care institutions. A commitment toward diversity needs to be made.
\end{abstract}

Keywords: diversity, inclusion, medical school admissions, admissions committee

\section{Introduction}

The US president Lyndon B Johnson launched the affirmative-action programs in 1965, stating: "You do not take a person who, for years, has been hobbled by chains and liberate him, bring him up to the starting line of a race and then say, 'You are free to compete with all the others', and still justly believe that you have been completely fair."1 Rather, President Johnson wanted ". . . not just equality as a right and as a theory but equality as a fact and equality as a result."1 The struggle continues to make equity a fact and a result. Through a series of legal decisions, including Supreme Court rulings, culminating in Grutter versus Bollinger, the rationale for efforts to develop a more equitable and inclusive educational milieu changed to be, in Supreme Court Justice Sandra Day O'Connor's words, “. . . obtaining the educational benefits that flow from a diverse student body", ${ }^{2}$ a shift in focus from what was beneficial for the individual
Correspondence: Reginald F Baugh Department of Surgery, School of Medicine and Life Sciences, University of Toledo, Mail Stop 1905, 3000 Arlington Avenue, Toledo, $\mathrm{OH} 43614$, USA Email reginald.baugh@utoledo.edu 
what was beneficial for all. However, as much as society has changed in the last 50 years, much of it remains the same. Still, the underrepresentation of some racial/ethnic groups in medicine today is rooted in the history of segregated and unequal education (kindergarten through medical school), ${ }^{55}$ as well as in the barriers to professional advancement, some of which continue in academic medicine, an education system in which racial/ethnic minorities receive poorer-quality education at every level, and a culture in which institutional and interpersonal racial discrimination remain a reality. ${ }^{1}$ Unlike some intractable problems facing the health-care system, diversity in medical schools can be understood as a problem of manageable magnitude that can be solved with the necessary will to do so because there is a clear pathway to such success.

\section{Institutional mission}

A growing body of research illustrates the importance of aligning efforts across the operational continuum to achieve diversity goals. This alignment begins with the institutional mission and the message it conveys about the priorities of the institution to potential applicants, community, staff, and faculty. ${ }^{4,5}$ Mission statements are meaningful statements about the values and intended direction of medical schools. ${ }^{8}$ The traditional themes of education, research, and service dominate most medical school mission statements. The emerging themes of physician maldistribution, overall primary-care physician shortage, diversity, and cost control are cited less frequently. Failure to cite these emerging themes may reflect the institutional leadership's lack of commitment to these issues, ${ }^{6,7}$ as the first and most fundamental tenet of a mission statement is to establish a vision that people can live up to, thus providing direction and purpose to its constituency. To the extent a mission statement is meaningful and reflective of its constituency's beliefs about institutional diversity, the constituents will follow the direction articulated in the mission, in order to achieve the purpose of the organization. Therefore, as an expression of vision and a reflection of the broader social environment in which it is embedded, any mission statement should have diversity as a major consideration.

Although including diversity and other emerging themes, such as social justice or health equity, in a mission statement does not guarantee results, omitting them may suggest that the institution has not fully, if at all, embraced these issues. ${ }^{9}$ When public commitments to social justice or social determinants of health are not present, physician graduates are less likely to choose to practice in underserved areas or help underserved populations. ${ }^{10}$ As such, to embrace societal responsibilities, institutions need to be proponents of diversity and inclusion, encourage their students to serve all patients, and embrace health equity.

\section{Institutional leadership}

The importance and salience of having administrative leaders with an explicit commitment to workforce and student diversity is a prominent and pivotal factor in the medical literature on the subject. Organizational leadership shapes the general work climate and expectations around diversity, recruitment, and retention. This leadership and commitment must extend beyond the deans' offices to departmental and divisional leaders. Extending accountability to the departmental level encourages intentional internal support and fosters a commitment to enhancing diversity. A piecemeal approach where diversity is only one department's responsibility may result in a "silo" approach, making diversity a principal issue for only certain groups or departments. ${ }^{3}$ Every effort must be made to integrate diversity plans and programs into the overall mission and fabric of the institution. When adversity comes, diversity and diversity programs are at risk if they are not core to the institution or its mission.

\section{Holistic review}

Following the Bakke decision, individual medical schools, supported by the Association of American Medical Colleges (AAMC), worked to expand the frame of reference for evaluating applicants for medical school. These efforts have come together under the rubric "holistic review", permitted by the US Supreme Court in 2003: “. . . a highly individualized, holistic review of each applicant's file, giving serious consideration to all the ways an applicant might contribute to a diverse educational environment." Under such an approach, a school seriously considers each "applicant's promise of making a notable contribution to the educational milieu by way of a particular strength, attainment, or characteristic, eg, an unusual intellectual achievement, employment experience, nonacademic performance, or personal background."2 What has evolved is a flexible, individualized way of assessing an applicant's capabilities by which balanced consideration is made on how the individual might contribute value as a medical student and physician. ${ }^{25}$

The first US adoption of holistic review occurred more than a decade ago, and today there are relatively few medical schools that are unaware of these principles. Four clear criteria have been associated with successful application of holistic approaches in medical schools over the last few 
years, ${ }^{25}$ although the focus has been on the first criterion: balancing applicant attributes, metrics, and experiences. It is hoped that by framing the decision process in this way that individual admission-committee members may overcome implicit bias and the previous dominance of academic metrics might be mitigated to encourage a more strategic approach to medical school student enrollment. However, this grouping of applicant factors into three large categories may be too superficial, and does not guarantee diversity, inclusion, or any other outcome. ${ }^{56}$

Much of the medical school literature regards holistic review as a positive tool that can be utilized to achieve greater diversity or inclusion in its incoming medical student classes. Like any tool, however, holistic review is neutral. How it is used is dependent upon the actions and desired intent of medical school leadership. It may be used to increase, maintain the status quo, or even decrease the diversity of incoming classes ${ }^{56}$ if desired. By obliquely considering "other factors" that are not explicitly stated, the intent is unable to be predicted or known. To achieve transparency, the factors considered and any weighting of those factors should be explicitly stated and readily available for public scrutiny.

\section{Applicant-selection methodologies}

A variety of methodologies are available for scoring personal attributes, experiences, and metrics that can be equitably applied to enhance diversity or other outcomes, such as rural selection, ${ }^{29}$ without changing minimum admission requirements or other academic metrics. ${ }^{30}$ There are over 30 distinct factors that can be categorized in different ways as attributes, experiences, and metrics. For example, a student's research can be judged based on its intellectual curiosity (attribute), the experience they had in the laboratory (experience), the type of journal it was published in, and their position on the authors' list (metric). Further, during the four opportunities for their consideration in the admission process (selection for secondary application, selection for interview, the interview, and the final deliberation), how much they are considered (weighting or threshold: yes or no), and who makes the decision (the whole or a subset of the admission committee) are considered, the opportunities for a spectrum of different outcomes are present, depending on how the decision process is structured. Modeling a variety of methodologies using a school's actual experience to determine the optimal methodology to meet the institutional mission and goals should be undertaken. Alternative approaches, such as beginning with the end in mind, develop a list of expectations regarding incoming freshmen, derive a list of constructs that are hypothesized to be essential for success, and then develop a series of measures to assess student potential and better represent the totality of relevant student outcomes, and may represent one of many alternative methodologies.$^{28}$ Regardless of the admission methodology utilized, it should value the noncognitive characteristics that seem much more important and prominent to practicing physicians, ${ }^{27}$ and probably the community, and rely less on past academic achievement. ${ }^{28}$

Ultimately, the admission process strives to identify those applicants who will become outstanding physicians. When an institution goes through the process to describe what holistic review means, they should be clear and accurate. What that means will depend upon the mission of the school and to whom and how it is defined. Desirable physician attributes identified in the ivory tower of academics have included intellectual ability, commitment to service, cultural sensitivity, empathy, capacity for growth, emotional resilience, strength of character, personal characteristics, curiosity, and engagement. ${ }^{26}$ However, when expert practitioners from a range of specialties selected attributes for physicians, they chose integrity, primacy of patient care, communication skills, empathy, lifelong learning, tolerance of ambiguity, and recognition of one's limitations..$^{27}$ These characteristics may reflect differences in what makes a successful student and what makes a successful physician, but what is most striking is the absence of intellectual ability as an important criterion for expert practitioners. Regardless of the factors chosen, their grouping, and any weighting scheme used, the factors should be explicitly detailed, publicly reported, and reviewed yearly by the appropriate committee to ensure transparency that the optimal outcome reflective of the school mission and robust diverse educational environment is achieved. Methodologies should value the noncognitive characteristics that seem more important and pertinent to practicing physicians and the community.

\section{Medical school applicants}

Prioritizing the institutional effort to recruit and retain diverse students is paramount, for without diverse applicants, no matter how unbiased and holistic a selection process is, an institution cannot achieve a diverse student body. A comprehensive strategic plan of recruitment and retention is favored over one that conflates recruitment with retention or one that offers short-term, purely economic incentives, such as scholarships, to applicants. The latter creates an 
environment where diversity can be purchased, as candidates are looking only to alleviate long-term debt, as educational debt is substantially higher for diverse students. ${ }^{2}$ As long as large-enough economic incentives are available, diversity will exist. When these incentives recede or are eliminated, the diversity pool becomes nonexistent, because there were no lasting organizational structures in place to ensure its continuance. Further, a scholarship-only strategy assumes that, "all things being equal", finances are the determining factor for applicants. A more insightful strategy envisions making the school more attractive to not only diverse candidates but to all candidates, because seldom are all things equal, except for financial issues.

Of the nine factors associated with favorable medical school selection, at least four are modifiable: interactions with students, faculty and staff; potential for student research; strong community links; and potential for faculty mentorship. Even when the focus is narrowed to just diverse candidates, the majority of the decisive selection factors are modifiable. ${ }^{23}$ Even the lay recommendations ${ }^{24}$ that reinforce selection factors identified by diverse students ${ }^{23}$ contain similar modifiable factors. These factors provide opportunities for possible intervention and improvement by medical schools. For example, a medical school that supports service and community outreach and ideally supports research that focuses on minority health or health-care disparities ${ }^{24}$ will likely be favored in diverse candidate selection.

A large diverse applicant pool is needed to ensure the appropriate candidates can be chosen for the incoming medical school class. Understanding the optimal rationale and components for a successful recruitment program is important. Benchmarking with other schools regionally and nationally will identify what should be the relative size of a pool. Ongoing awareness campaigns should also be undertaken to maintain the existing size of the pool and to continue to attract outstanding candidates. Identifying where deficiencies in the applicant pool exist will permit more specific and effective initiatives to increase diversity. The availability of qualified applicants who are interested in your school is the ultimate objective. Building opportunities for personal interaction between applicants and faculty, students, and administration during the interview process is an integral component in recruitment. Along with this, schools should strive to maintain regular personal contact with their diversity pool. The ultimate objective is to maintain (if not increase) the availability of qualified applicants that are interested in a medical school, as well as raise a school's status on an applicant's consideration list.
As medical schools allocate attention and resources to recruiting, they should also consider the resources needed for support services for all students. Efforts to enhance access are vital, but recruitment initiatives should not be conflated with efforts to improve an institution's capacity to address the quality of the context in which students engage with diversity. ${ }^{15}$ Integrated curricula present opportunities to include experiential learning, content, and skills that would be useful to attract diverse students who want to help their communities. Sole dependence upon volunteer and student-run programs for recruitment or student support will guarantee long-term failure.

\section{Role of diversity}

Recent advances in understanding diversity and its relationship to students allow greater insight into what needs to be accomplished with diversity programs. Compared with other forms of diversity, racial and ethnic diversity is uniquely associated with students' perceptions of learning from others who are different. Other forms of diversity do not appear to have this same potency of association or capacity to enhance the educational environment. ${ }^{13}$ It was once thought that there was a positive linear relationship between diversity exposure and the educational environment, suggesting that even a small amount of diversity had a beneficial effect. Recent research has called these beliefs into question. In one study, 8,615 first-year students at 49 different colleges and universities were followed. Results indicated that rare or moderate diversity interactions were associated with virtually no growth and sometimes even slight declines in leadership skills, psychological wellbeing, and intellectual engagement in the student body, all characteristics that institutions aim to enhance in their students. In contrast, very frequent diversity interactions were associated with considerable growth in those attributes. Similar results were seen throughout the study, regardless of students' race or institutional characteristics. ${ }^{14}$ The impact of diversity is based not only on quality but also quantity, and thus institutions need to be aware of the importance of critical mass in diversity efforts. Increased diversity in medical schools will increase the likelihood of patient-physician concordance, a shared demographic identity or beliefs between the physician and the patient, which results in improved relationships, patient satisfaction, trust, and patient adherence to physician recommendations. These factors ultimately are thought to be impactive in the fight against health disparities. ${ }^{3}$ 


\section{Critical mass}

In nuclear physics, critical mass is the amount of fissionable material needed to initiate a chain reaction. Recent work in the social sciences has put a number on the insightful words of Margaret Mead: "Never doubt that a small group of thoughtful, committed citizens can change the world; indeed, it's the only thing that ever has." If opinions are reflective of attitudes, and attitudes of behaviors, then about $10 \%$ is the proportion of a population needed. When $10 \%$ of a population strongly holds a minority opinion, it rapidly becomes the majority opinion. Several conditions must be present before the rapid change occurs: committed proselytes, randomly distributed throughout the population actively engaging the majority in an ongoing fashion. ${ }^{4}$ Translated to medical school classes, institutions would need $10 \%$ of diversity students passionately committing to diversity goals and actively engaging the uncommitted. Unfortunately, none of the conditions is met, and nor is this percentage commonplace in medical school classes. Not achieving a critical mass of diverse students has consequences that extend beyond the students themselves.

The critical mass necessary to achieve "educational benefits that flow from a diverse student body" remains to be defined precisely. A recent review of the social and learning environments experienced by diverse students in medical school strongly suggests that those educational benefits do not flow in their direction. Rather, the environments experienced by diverse students were more negative than those experienced by white students, ${ }^{1}$ and it appeared to get worse over time. ${ }^{5}$ Minimal improvements have yet to occur, as studies continue to demonstrate that African-American, Latino, female and "lesbian/gay/bisexual/transgender/queer" respondents have lower degrees of engagement than their counterparts. ${ }^{11,12}$

Of the three identified time-honored principles to improve diversity and close the health-profession gap (culture, improving pathways to schools, leadership commitment), culture is often the most neglected precondition for success. ${ }^{6}$ The context in which students interact and learn is open to specific engineering in the curriculum. Avenues that have been previously utilized in this context are experiential learning and group activities and discussions. All subtle curriculum changes that place students on an equal footing with one another when they interact are helpful, yet the literature on successful interventions to improve the educational or social environment for diverse students remains weak and increasingly dated. ${ }^{1}$ Regardless, medical schools are accountable for the educational environment they specifically engender, since the goal of the totality of educational endeavor is to create a conducive educational environment for all students to achieve the stated educational goals.

So where are we? We know that the racial makeup of the incoming classes is of paramount importance. We know that small numbers are ineffectual and that a critical mass needs to be achieved. We know that a common cultural background will be a cultural multiplier that will increase the likelihood of success. We know that considering immigrants or naturalized citizens as native-born students is unlikely to result in the same outcomes as native-born candidates, because of differences in culture. Even with this knowledge, the unique circumstances of every school, its mission, and class characteristics make any universal formula inadequate. To ensure the benefits associated with diversity, the quality of student interactions, and their perceptions of the diversity climate should be important considerations.

\section{Role of faculty}

The recruitment and maintenance of diverse faculty is integral to the development of diversity throughout an institution. A diverse faculty facilitates the recruitment of all students and residents, plays a key role in their education training, and fosters an environment conducive to advancement and development. All students deserve the opportunity to interact with people reflective of the nation and community in which they will serve.

Medical school faculty members are key to reducing health disparities, a point underscored by the American College of Physicians in 2004. ${ }^{17}$ In addition, the presence of diverse physicians in academic medicine can improve minority health and reduce health disparities through a variety of mechanisms, including accelerating medical and public health research, training students and residents to provide culturally competent care, ${ }^{18}$ and providing medical and health-policy leadership that improves organizational processes. ${ }^{19}$

The proportion of minority students 10 years prior showed correlation with minority faculty representation, suggesting that enhancing the pipeline of diverse students to medical school or specific resident-recruitment activities could be an effective long-term strategy to increasing diverse faculty representation..$^{20}$ Other ways to recruit a diverse faculty could be through social networks, diversity committees, or faculty interpersonal connections. Tapping into African-American or Latino professional organizations (eg, Society of Black Academic Surgeons, National Hispanic Medical Association, and National Medical Association) could also be utilized to identify potential faculty candidates. School leadership 
attending and/or participating in diverse organizations' meetings, such as the National Medical Association, demonstrate much more of a commitment than a simple letter or job posting ever could.

Successful strategies for underrepresented in medicine (URIM) faculty recruitment and retention include institutional leadership, the use of human capital and social relationships, and strategic deployment of institutional resources. ${ }^{21}$ While there have been advances in the last decade in the recruitment of African-Americans and other people of color within the ranks of US medical schools, complacency should be avoided. At the current national rate of minority admittance, it would take nearly 1,000 years for the proportion of African-American physicians in academic medicine to catch up to the percentage of African-Americans in the general population. ${ }^{21}$

\section{Premedical experience}

The premedical experience for students from underrepresented backgrounds needs to be addressed in plans for increasing diversity in medical schools or other health professions. Coming from a shallow reservoir, many diverse students leak from the medical school pipeline during their undergraduate educational experiences, because they are underprepared to endure the challenges of the premedical curriculum. High schools serving students of color are less likely to offer advanced-placement courses and gifted programs when compared with schools serving predominantly white populations. Of the schools that have these options, students of color are less likely than their white peers to be enrolled in those courses. ${ }^{31,32}$ Just under one in five AfricanAmerican high school students attend a high school that offers advanced-placement courses, a higher proportion than any other racial group. ${ }^{33}$ First-generation African-American or Hispanic college students from low-income families are more likely to be underprepared, because they have not taken higher-level math and science courses prior to entering college. ${ }^{34}$ This does not mean that they are unworthy to become physicians, but implies that they are unprepared for the journey's end. Education research demonstrates that students from all backgrounds benefit from intentional firstyear programs, frequent interaction with faculty, and career exploration. Notably, it is underprepared students who appear to benefit the most from these practices. ${ }^{38}$

Undergraduate schools sometimes employ special intentional programs to prevent incoming students from abandoning their aspirations of attending medical school, ${ }^{39}$ thereby fixing the leaky pipeline for African-American students and other diverse students. Historically, chemistry courses are often the ones that cause diverse science, technology, engineering, and mathematics (STEM) students to abandon aspirations of becoming a physician. Intentional, directed support may prevent otherwise-acceptable applicants from changing their career aspirations. ${ }^{40}$ Xavier University in Louisiana, for example, has been the exemplary diverse-undergraduate premedical program for over a decade. ${ }^{43}$ It has consistently ranked first in the nation regarding the number of AfricanAmerican college graduates who go on to medical school. A plethora of intentional undergraduate premedical programs are readily available for review. ${ }^{3,41}$ The success of these types of programs suggests that many diverse undergraduate candidates are underprepared, but able to achieve STEM success, and that more effort should be spent on fixing the existing pipeline, rather than building new ones.

Undergraduate advising plays a pivotal role for diverse students who have fewer resources available to them from knowledgeable friends or family regarding undergraduate coursework and medical school admissions and selection practices. Often, these students may experience challenges in the transition from high school to college, because of family financial struggles and lack of parental guidance. ${ }^{35-37}$ Therefore, greater reliance is placed upon undergraduate counseling to address the gap and equalize the playing field for diverse undergraduate students. Unfortunately, too often undergraduate counseling is neither aware of nor tailored to diverse-student needs. It is important for undergraduate advising to include guidance about appropriate summer activities, extracurricular involvement, the medical school application process, preparation for the Medical College Admission Test (MCAT), and preparation for medical school interviews. $^{42}$

\section{Pipeline programs}

Pipeline programs are often viewed as the key long-term strategy for the identification of future medical students. From as early as high school, underrepresented students are supported and mentored in an effort to increase minority matriculation into medical schools. These programs can either be inspirational and focus on increasing awareness of a career in health care, or developmental and focus on enhancing the skills and preparation of its participants. Although both will increase the pool of applicants, the latter (properly executed) will more likely enhance the applicant pool in a shorter time frame and have different milestones.

Relationships between medical schools and pipeline programs are required to maintain a diverse applicant pool. 
They must be cultivated consistently over time, necessitating a stable and robust funding base..$^{22}$ Experience has shown that direct personal contact between medical school personnel and representatives of individual institutions is critical for the success of collegiate-pipeline efforts. Interactions on an ad hoc basis between medical school personnel and student groups are less effective, because of their transient nature, limited duration, and limited reach. ${ }^{3}$ If a medical school establishes and maintains a relationship with a premedical counselor, they have established a relationship with potentially scores of premedical students over years. Both strategies need to be employed synergistically to achieve optimal outcomes.

Such programs as Faces for the Future highlight the value of inspirational and developmental pipeline programs for high school students. Between 2013 and 2015, 45 students from Hayward, California were accepted into the program: $62 \%$ were at or below the federal poverty line, $25 \%$ had a history of homelessness, $76 \%$ had incarcerated friends and family, $80 \%$ were from fractured families due to divorce, abandonment, or immigration issues, $39 \%$ would be the first of the family to graduate from high school, and 95\% had experienced difficulties in both the home and the community. As a group, the students represented 14 ethnicities, spoke seven languages, and more than two-thirds of them were either bilingual or multilingual. When they began, $77 \%$ of them were not on track to graduate from high school. With the proper intervention, support, and coordinated services, all the students graduated from high school and were accepted to college. Despite the astonishing success of the program, the expected number of baccalaureate graduates for these students would be perhaps eight or nine students. Not all of the student graduates would have the desire or academic metrics to compete successfully for admission to medical school. Understanding that the long-term success of many programs targeting high school students is something less than $20 \%$ in any graduate school (not just medical school) in a decade highlights the need for other vehicles to achieve the ideal enrollment in diversity programs.

\section{Undergraduate postbaccalaureate programs}

Undergraduate postbaccalaureate preparatory programs are pivotal among medical school efforts to increase diversity across the country. However, some schools are ambivalent about postbaccalaureate programs. Such concerns should be explored and appropriately addressed. ${ }^{53}$ The belief that postbaccalaureate applicants have not earned consideration and somehow are not qualified for medical school is incorrect.
Broader long-term data from the National Post-Baccalaureate Consortium have shown that postbaccalaureate graduates have gone on to exemplary careers in every specialty. They were also more likely to provide care in federally designated underserved areas and to practice in institutional settings where vulnerable populations had access to care. ${ }^{50}$

Ohio State University (OSU), ranked among the top 20 public universities in the US and 34th in the US News and World Report's list of "Best global universities", is the nation's most comprehensive research university ${ }^{48}$ and achieved a 91\% success rate for students whose MCAT score average was less than the 45 th percentile through their postbaccalaureate program. ${ }^{22}$ While the floor for academic metrics is unique to each school, the most prominent factors in overall student success are the quality of instruction and support services. That same year of OSU's success rate, AAMC statistics showed that only $20 \%$ of national students with MCAT scores equal to or lower than graduates from OSU's postbaccalaureate were admitted to medical school. ${ }^{49}$ Such findings as this would suggest that a significant number of valuable applicants to medical school are presumably not admitted because of a lack of adequate support services.

Some researchers have posited that medical school desires to garner top ranking on consumer-reporting services, such as the US News and World Report, may be at odds with efforts to increase diversity. ${ }^{51}$ Indeed, a review of the most recent US News and World Report Best medical school ranking methodology finds "student selectivity" accounting for $20 \%$ or less of the total ranking for most of the medical schools in the US. Closer scrutiny of the US News and World Report methodology reveals that less than 2\% of the overall nonresearch rankings are attributable to actual student characteristics: median MCAT scores, median grade-point average, or acceptance rate. In comparison, the ratio of fulltime basic science and clinical faculty to medical students is the much-larger portion of this section, accounting for $15 \% .{ }^{52}$ Clearly, focusing on student factors is largely inconsequential compared to the role of the number of full-time basic science and clinical faculty, and is not likely materially to affect the ranking of over half the medical schools in the US.

\section{Living-learning communities}

There is convincing evidence that participation in livinglearning communities associated with health care and STEM programs at the undergraduate level is associated with many positive outcomes, including smoother academic transitions to college and an increased sense of belonging. ${ }^{45,46}$ In addition, URIM and first-generation students demonstrate increased 
benefits from participating in living-learning communities with a STEM focus. ${ }^{46}$ For URIM, first-generation college students, and underprivileged students, faculty involvement in these communities may be their only outlet to share their college experience, thereby improving retention. As such, significant efforts should be directed toward connecting first-generation URIM and disadvantaged students with faculty. ${ }^{47}$ Integration of the faculty into the residence-hall environment facilitates student feedback from faculty and avoids feelings of inadequacy and anxiety that accompany delays in communication.

\section{Conclusion}

Diversity is of compelling interest to us all, and should pervade all aspects of higher education, including admissions, the curriculum, student services and activities, and our faculties. ${ }^{54}$ The aim of medical education is to cultivate a workforce with the perspectives, aptitudes, and skills needed to fuel community-responsive health-care institutions. A commitment toward diversity needs to be made. Otherwise, these thoughts and beliefs being expressed are only an interest that lasts as long as it is convenient. That commitment should translate into concrete plans and resources for diversity efforts. "Diversity" should be a noun reflecting facts, not a verb reflecting intentions, real or imagined.

\section{Disclosure}

The authors report no conflicts of interest in this work.

\section{References}

1. Johnson LB. Howard University commencement address. 1965. Available from: http://www.presidency.ucsb.edu/ws/?pid=27021. Accessed November 8, 2017.

2. US Supreme Court. Grutter v. Bollinger, 539 U.S. 306. 2003. Available from: https://supreme.justia.com/cases/federal/us/539/306/case.html. Accessed November 8, 2017.

3. Deas D, Pisano ED, Mainous AG 3rd, et al. Improving diversity through strategic planning: a 10-year (2002-2012) experience at the Medical University of South Carolina. Acad Med. 2012;87(11):1548-1555.

4. Conrad SS, Addams AN, Young GH. Holistic review in medical school admissions and selection: a strategic, mission-driven response to shifting societal needs. Acad Med. 2016;91(11):1472-1474.

5. Taylor T, Milem J, Coleman A. Bridging the Research to Practice Gap: Achieving Mission-Driven Diversity and Inclusion Goals. New York: College Boards; 2016.

6. Fair M, Arceneaux MT. How can academic medical centers and teaching hospitals address the social determinants of health? Acad Med. 2016;91(3):443.

7. HealthyPeople.gov. Increase the inclusion of cultural diversity content in M.D.-granting medical schools. 2008. Available from: https://www. healthypeople.gov/node/4183/data_details. Accessed November 8, 2017.

8. Grbic D, Hafferty FW, Hafferty PK. Medical school mission statements as reflections of institutional identity and educational purpose: a network text analysis. Acad Med. 2013;88(6):852-860.

9. Valsangkar B, Chen C, Wohltjen H, Mullan F. Do medical school mission statements align with the nation's health care needs? Acad Med. 2014;89(6):892-895.
10. Morley CP, Mader EM, Smilnak T, et al. The social mission in medical school mission statements: associations with graduate outcomes. Fam Med. 2015;47(6):427-434.

11. Royal KD, Cannedy AL, Dent GA. More on diversity and inclusion in academic medicine: the isolation of black females. Acad Med.2016;91(7):896.

12. Person SD, Jordan CG, Allison JJ, et al. Measuring diversity and inclusion in academic medicine: the Diversity Engagement Survey. Acad Med. 2015;90(12):1675-1683.

13. Morrison E, Grbic D. Dimensions of diversity and perceptions of having learned from individuals from different backgrounds: the particular importance of racial diversity. Acad Med. 2015;90(7):937-945.

14. Bowman NA. How much diversity is enough? The curvilinear relationship between college diversity interactions and first year student outcomes. Res High Educ. 2013;54(8):874-894.

15. Denson N, Chang MJ. Dynamic relationships: identifying moderators that maximize benefits associated with diversity. JHigher Educ. 2015;86(1):1-37.

16. Nunez-Smith M, Curry LA, Bigby J, Berg D, Krumholz HM, Bradley $\mathrm{EH}$. Impact of race on the professional lives of physicians of African descent. Ann Intern Med. 2007;146(1):45-51.

17. Groman R, Ginsburg J. Racial and ethnic disparities in health care: a position paper of the American College of Physicians. Ann Intern Med. 2004;141(3):226-232.

18. King TE Jr, Dickinson TA, DuBose TD Jr, et al. The case for diversity in academic internal medicine. Am J Med. 2004;116(4):284-289.

19. Cohen JJ, Gabriel BA, Terrell C. The case for diversity in the health care workforce. Health Aff (Millwood). 2002;21(5):90-102.

20. Yu PT, Parsa PV, Hassanein O, Rogers SO, Chang DC. Minorities struggle to advance in academic medicine: a 12-y review of diversity at the highest levels of America's teaching institutions. J Surg Res. 2013;182(2): 212-218.

21. Suburban Stats. Population demographics for Toledo, Ohio. 2017. https://suburbanstats.org/population/ohio/how-many-people-live-intoledo. Accessed November 8, 2017.

22. Capers Q, Way DP. Academic and post-graduate performance of African American medical students by category of premed institution: historically black vs. predominantly white institutions. $J$ Health Care Poor Underserved. 2015;26(3):617-630.

23. Smith-Barrow D. "Consider medical school choice carefully as a minority student. 2013. Available from: https://www.usnews.com/education/best-graduate-schools/top-medical-schools/articles/2013/04/15/ consider-medical-school-choice-carefully-as-a-minority-student. Accessed November 8, 2017.

24. Smith-Barrow D. Which medical schools interview the most minority applicants? 2015. Available from: https://www.usnews.com/education/ best-graduate-schools/top-medical-schools/articles/2015/08/25/whichmedical-schools-interview-the-most-minority-applicants. Accessed November 8, 2017.

25. Witzburg RA, Sondheimer HM. Holistic review: shaping the medical profession one applicant at a time. N Engl J Med. 2013;368(17):1565-1567.

26. Lambe P, Bristow D. What are the most important nonacademic attributes of good doctors? A Delphi survey of clinicians. Med Teach. 2010;32(8): e347-e354.

27. Schmit N. Development of rationale and measures of noncognitive college student potential. Educ Psychol. 2012;47(1):18-29.

28. Raghavan M, Martin BD, Roberts D, Aoki F, MacKalski BA, Sandham JD. Increasing the enrollment of rural applicants to the faculty of medicine and addressing diversity by using a priority matrix approach to assign values to rural attributes. Rural Remote Health. 2011;11(2):1646.

29. Ballejos MP, Rhyne RL, Parkes J. Increasing the relative weight of noncognitive admission criteria improves underrepresented minority admission rates to medical school. Teach Learn Med. 2015;27(2): $155-162$.

30. Adelman C, Kao G, Thompson JS. Racial and ethnic stratification in educational achievement and attainment. Annu Rev Sociol. 2003;29:417-442.

31. Adelman C. Answers in the Tool Box: Academic Intensity, Attendance Patterns and Bachelor's Degree Attainment. Washington: US Department of Education; 1999. 
32. Handwerk P, Tognatti N, Coley RJ, Gitomer DH. Access to success: patterns of advanced placement participation in US high schools. 2008 Available from: https://www.ets.org/Media/Research/pdf/PIC-ACCESS. pdf. Accessed November 8, 2017.

33. Chen XL. First-Generation Students in Postsecondary Education: A Look at Their College Transcripts. Washington: National Center for Education Statistics; 2005.

34. Jury M, Smedig A, Court M, Darnon C. When first-generation students succeed at university: on the link between social class, academic performance and performance avoidance goals. Contemp Educ Psychol. 2015;41:25-36.

35. Lundburg C. Predictors of learning for students from five different racial/ethnic groups. J Coll Stud Dev. 2012;53(5):636-655.

36. Pascarella ET, Pierson CT, Wolniak GC, Terenzini PT. First-generation college students: additional evidence on college experiences and outcomes. J Higher Educ. 2004;75(3):249-284.

37. Kuh GD. High-Impact Educational Practices: What They Are, Who Has Access to Them, and Why They Matter. Washington: Association of American Colleges and Universities; 2008.

38. Miretzky D, Chennault RE, Fraynd DJ. Closing an opportunity gap Educ Urban Soc. 2016;48(1):48-76.

39. Morgan HK, Haggins A, Lypson ML, Ross P. The importance of the premedical experience in diversifying the health care workforce. Acad Med. 2016;91(11):1488-1491.

40. Freeman BK, Landry A, Trevino R, Grande D, Shea JA. Understanding the leaky pipeline: perceived barriers to pursuing a career in medicine or dentistry. Acad Med. 2016;91(7):987-993.

41. Hannah-Jones N. A prescription for more black doctors. 2015. Available from: http:/www.nytimes.com/2015/09/13/magazine/a-prescriptionfor-more-black-doctors.html. Accessed January 4, 2017.

42. Inkelas KK, Daver ZE, Vogt KE, Leonard JB. Living-learning programs and first-generation college students academic and social transition to college. Res High Educ. 2007;48(4):403-434.

43. Soldner M, Rowan-Kenyon H, Inkelas KK, Garvey J, Robbins C. Supporting students' intention to persist in STEM disciplines: the role of living learning programs among other social cognitive factors. J Higher Educ. 2012;83(3):311-336.

44. Hausman L, Schofield JW, Woods RL. Sense of belonging as a predictor of intention to persist among African-American and white first year college students. Res High Educ. 2007;48(7):803-839.
45. Komarraju M, Musulkin S, Bhattacharya G. Role of student-faculty interactions and developing college students' academic self-concept, motivation and achievement. J Coll Stud Dev. 2010;51(3): $332-342$.

46. US News and World Report. Ohio State University. 2017. Available from: http://grad-schools.usnews.rankingsandreviews.com/bestgraduate-schools/top-medical-schools/ohio-state-university-04089. Accessed November 8, 2017.

47. Dunleavy D, Sondheimer H, Castillo-Page L, Bletzinger RB. Medical school admissions: more than grades and test scores. 2011. Available from: https://www.aamc.org/download/261106/data. Accessed November 8, 2017.

48. Ohio State University. Medpath program. Available from: https:// medicine.osu.edu/students/diversity/Programs/medpath/Pages/index. aspx. Accessed November 8, 2017.

49. McDougle L, Way DP, Lee WK, et al. A national long-term outcomes evaluation of U.S. premedical postbaccalaureate programs designed to promote health care access and workforce diversity. J Health Care Poor Underserved. 2015;26(3):631-647.

50. Heller CA, Rua SH, Mazumdar M, Moon JE, Bardes C, Gotto AM. Diversity efforts, admissions, and national rankings: can we align priorities? Teach Learn Med. 2014;26(3):304-311.

51. Grumbach K. Adopting postbaccalaureate premedical programs to enhance physician workforce diversity. Acad Med. 2011;86(2):154-157.

52. Chun E, Evans A. The educational benefits of diversity: who gains? In: Affirmative Action at a Crossroads: Fisher and Forward. Hoboken (NJ): Wiley; 2015:39-56.

53. Girotti JA, Park YS, Tekian A. Ensuring a fair and equitable selection of students to serve society's health care needs. Med Educ. 2015;49(1): 84-92.

54. Mensah MO, Sommers BD. The policy argument for healthcare workforce diversity. J Gen Intern Med. 2016;31(11):1369-1372.

55. Cook L. U.S. education: still separate and unequal. U.S. News \& World Report. 2015 Jan 28;Data MINE.

56. Zell JR. It's Not About race: the true purpose of the University of Texas' Holistic- Admissions System is to give preferences to wellconnected White applicants, not to disadvantaged minorities. Available from: https://business-law-review.law.miami.edu/wp-content/ uploads/2016/04/Zell-Final-PDF.pdf. Accessed August 01, 2017.
Advances in Medical Education and Practice

\section{Publish your work in this journal}

Advances in Medical Education and Practice is an international, peerreviewed, open access journal that aims to present and publish research on Medical Education covering medical, dental, nursing and allied health care professional education. The journal covers undergraduate education, postgraduate training and continuing medical education

\section{Dovepress}

including emerging trends and innovative models linking education, research, and health care services. The manuscript management system is completely online and includes a very quick and fair peer-review system. Visit http://www.dovepress.com/testimonials.php to read real quotes from published authors. 